\title{
Consultation and Coaching to Increase the Uptake of Evidence- Based Practices: Introduction to the Special Issue
}

\author{
Brandon K. Schultz • Prerna Arora • \\ Jennifer A. Mautone
}

Published online: 11 February 2015

(c) Springer Science+Business Media New York 2015

\begin{abstract}
Traditional approaches to school consultation involve a voluntary, collaborative relationship between a consultant and teacher consultee to develop interventions for students with special needs, often over long periods, with ongoing problem solving and performance feedback. However, with the advent of multi-tiered systems of support, school consultation has evolved into a strategy to support the systemic adoption of evidence-based practices (EBPs). With this shift, consultants increasingly fulfill the role of coach, moving beyond traditional collaborative relationships to address the professional development needs of consultees. Consequently, researchers examining school consultation have moved beyond questions of feasibility and acceptability and have entered a new era of implementation science. This special issue of School Mental Health examines contemporary applications of school consultation and coaching in support of EBP implementation. The five original research articles in the special issue advance the literature in this developing field.
\end{abstract}

B. K. Schultz (凶)

East Carolina University, Greenville, NC, USA

e-mail: schultzb@ecu.edu

P. Arora

Pace University, New York, NY, USA

P. Arora

University of Maryland School of Medicine, Baltimore, MD, USA

J. A. Mautone

Perelman School of Medicine at the University of Pennsylvania,

Philadelphia, PA, USA

J. A. Mautone

Children's Hospital of Philadelphia, Philadelphia, PA, USA
Keywords Consultation $\cdot$ Coaching $\cdot$ School mental health - Implementation science

As documented by the relevant literature, most children and adolescents with impairing mental health needs do not receive clinical services (Greenberg et al., 2003). In response, several national reform efforts in both education and mental health have called for the expansion of school-based mental health services (e.g., National Association of School Psychologists, 2008; President's New Freedom Commission on Mental Health, 2003), but unfortunately, when school-based services are available, evidence-based practices (EBPs) are used inconsistently (Forman et al., 2013). Despite widespread recognition that school-based services circumvent traditional barriers to care and are valued among stakeholders (e.g., Burns et al., 1995; Rones \& Hoagwood, 2000), our knowledge about the variables that promote or inhibit implementation of EBPs in schools is still limited (Owens et al., 2013). Over the past decade, the school mental health movement has moved beyond simple questions of whether school-based services are feasible and into a new era of implementation science focusing on strategies to support the uptake, evaluation, and sustainment of EBPs in schools (Eccles \& Mittman, 2006; Forman et al., 2013). In short, the field is in transition.

Consistent with the tenets of implementation science, researchers are increasingly interested in the systemic factors that interact with the individual characteristics of children, parents, and educators to affect implementation outcomes (Raver et al., 2009). Program developers report several factors that facilitate the implementation of EBPs in schools, including teacher and administrator support, integration of interventions within school curricula, and 
ongoing training to reinforce new skills. Conversely, barriers to implementation include (but are not limited to) time constraints, beliefs about the use of psychosocial interventions in schools, and competing job demands (Forman, Olin, Hoagwood, Crowe, \& Sake, 2009). Among the potentially malleable factors impacting EBP implementation, provider training is often highlighted as a promising means to facilitate the uptake of EBPs (e.g., Fixsen, Naoom, Blase, Friedman, \& Wallace, 2005; Greenhalgh, Robert, MacFarlane, Bate, \& Kyriakidou, 2004), partially because there are too few providers adequately trained in the use of EBPs (Kazdin, 2008; Weissman et al., 2006). Still, given the myriad of implementation barriers in schools, training alone is unlikely to produce consistent and sustained change (cf. Beidas \& Kendall, 2010). Rather, successful implementation often requires flexibility and persistence.

\section{Consultation and Coaching}

School consultants are trained professionals who assist teachers and other school-based professionals (hereafter, consultees) during the implementation of new practices. Traditionally, school consultation has been viewed as a partnership between two professionals (e.g., a mental health consultant and a classroom teacher) voluntarily collaborating to design and implement interventions for students with special needs. Consultation of this nature typically follows a problem-solving approach, often targeting individual student needs with customized interventions (Schultz, Reisweber, \& Cobb, 2008). However, consultation has evolved in recent years to resemble a coaching relationship. Similar to traditional consultation, a coach engages consultees in problem solving, observes their implementation efforts, and provides performance feedback, but coaching has the added aim of professional development (Ravthon, 2008; van Oorsouw, Embregts, Bosman, \& Jahoda, 2009). Accordingly, coaches assist in the training and guidance of specific EBPs, often in support of early career consultees or system-level change. The coaching relationship is unlike the collaborative partnership of conventional consultation because the unparalleled expertise of the coach creates a hierarchical-perhaps even supervisory-relationship. Coaching supplants the outmoded train-and-hope approach of traditional staff development models and takes on special importance in the context of multi-tiered systems of support (see Erchul, this issue).

Research suggests that coaching is effective at (a) increasing consultee knowledge; (b) strengthening both consultants' and consultees' skills (e.g., Capella et al., 2012; Miller, Yahne, Moyers, Marinez, \& Pirritano, 2004); and (c) improving youth outcomes (e.g., Capella et al.,
2012; Mashburn, Downer, Hamre, Justice, \& Pianta, 2010; Schoenwald, Sheidow, \& Letourneau, 2004). Theoretically, these successes are attributable to improved treatment integrity, which is the degree to which consultees implement an intervention as intended (Noell et al., 2000). For example, coaching appears to result in increased consultee adherence to EBP protocols (Becker, Bradshaw, Domitrovich, \& Ialongo, 2013; Schoenwald et al., 2004; Solomon, Klein, \& Politylo, 2012), at least while coaching is underway. Still, more research is needed to clarify how consultation/coaching efforts improve the implementation of EBPs in schools.

\section{The Special Issue}

Although School Mental Health has published many articles examining school consultation and coaching to date, this is the first compilation of solicited articles looking specifically at the connections between consultation/coaching and the implementation of EBPs. This topic was proposed by the attendees of the 2013 School Mental Health Research Summit in Washington, DC, preceding the annual conference of the Center for School Mental Health (CSMH; http://csmh.umaryland.edu/). At the research summit, the theme of school consultation and coaching emerged as a primary interest for researchers across an array of school mental health topics. Most participants agreed that consultation and coaching strategies are promising for the implementation of EBPs in schools, even though the relevant literature is still in its infancy. The special issue represents an attempt to advance the knowledge base with five original research articles examining school consultation and coaching.

In the first article, Shernoff, Lakind, Frazier, and Jacobsons (2015) examined a coaching intervention to support early career teachers' use of evidence-based classroom management and student engagement strategies to address the needs of students in high-poverty urban elementary schools. Using a mixed-method design, the authors evaluated adherence to, and feasibility of, the coaching intervention. As is often the case in urban settings, time and resource constraints posed serious challenges, so the authors present several considerations for overcoming those barriers to ensure EBP implementation. The authors' model for supporting early career teachers may also be helpful in reducing teacher stress and improving job satisfaction, potentially contributing to improved retention of highquality teachers in urban schools.

In the second article, Sutherland, Conroy, Vo, and Ladig (2015) examined practice-based coaching used in BEST in CLASS, a secondary prevention (i.e., Tier 2) intervention addressing problem behaviors in young children at risk of 
emotional and behavioral disorders. The results of this randomized control trial suggest that practice-based coaching improves teachers' use of evidence-based strategies during the program and at follow up, illustrating a promising approach to support the professional development of early childhood educators. The authors also examined child outcomes and found that the program addressed some needs of children at risk of emotional and behavioral difficulties. Pending further investigation and replication, BEST in CLASS may prove effective in the prevention of problems that would otherwise require costly tertiary interventions in elementary schools and beyond.

In the third article, Coles, Owens, Serrano, Slavec, and Evans (2015) examined a multi-component consultation model designed to address teacher knowledge, skills, and beliefs related to classroom behavior management. The authors described two specific consultation cases where teachers implemented a daily report card (DRC) to address classroom behavior problems in elementary school settings. The authors identified specific factors affecting teachers' classroom management (i.e., teacher beliefs and skills) that were both responsive to intervention and potentially instrumental in subsequent student behavior change. If the authors' results are replicated, their findings have meaningful implications for how consultants address teacher needs to ensure optimal student outcomes. It is also worth noting that the findings offer initial support for a relationship between their approach to consultation and student outcomes - a connection rarely examined in the literature due to its complexity.

In the fourth article, Cook, Lyon, Kubergovic, Wright, and Zhang (2015) directly addressed educator beliefs and attitudes toward EBPs using a supportive intervention integrated into a professional development series. In a preliminary analysis of data from 62 elementary schools, findings suggested that coaches consider beliefs to be a critical target for intervention in system-wide efforts to roll out EBPs. In addition, the supportive beliefs intervention that the authors tested appears to be a promising approach to altering consultee impressions of EPBs, which in turn might relate to improved program fidelity. As the authors note, system-wide uptake and sustainability of EBPs requires a multifaceted approach; the inclusion of consultee beliefs and attitudes as intervention targets may prove to be a vital component of successful implementation.

In the fifth article, Pas et al. (2015) examined the factors related to coaching dosage during the implementation of the PAX Good Behavior Game (GBG). In this study, coaches were free to provide varying schedules of support during a randomized control trial of the GBG. The authors analyzed several consultee characteristics associated with high-dose versus low-dose coaching and found that highdose consultees were more likely than low-dose consultees to report professional burnout and low self-efficacy prior to coaching. High-dose consultees were also more likely than their low-dose counterparts to be engaged in multiple systemic changes in their schools. These findings suggest that coaches adjusted their approach based on characteristics of the consultee and the needs of the setting. The results also suggest that low-dose coaching led to relatively fewer uses of the intervention in the classroom, even though competency with the GBG was established. These findings underscore the complexities of the dose-response relationship in consultation/coaching, pointing to the importance of factors extraneous to the specific intervention that can complicate coaching efforts.

We conclude the special issue with an invited commentary by Erchul (2015). Dr. Erchul has been at the forefront of research on school consultation and coaching over the past 25 years. One of his research interests has been social influence within consultation, including how consultants encourage meaningful behavior change among consultees. In a series of studies, Dr. Erchul and his colleagues (Erchul \& Raven, 1997; Erchul, Raven, \& Ray, 2001; Erchul, Raven, \& Whichard, 2001; Erchul et al., 2004) showed that consultants exert multiple influences within the consultative relationship, including the strength of their perceived expertise and the degree to which consultees anticipate desirable outcomes. Dr. Erchul's experiences seem particularly pertinent to our collection of articles, given the nature of contemporary coaching approaches and the changing role of consultants. As models of consultation increasingly focus on the implementation of EBPs within tiered prevention models, the social power bases available to consultants are likely to shift, requiring careful attention to how school consultees perceive the messages and support offered by consultants.

\section{Conclusion}

We believe the articles in the special issue exemplify the shift in the consultation literature toward coaching strategies. Specifically, all of the authors examined consultee factors related to implementation success, including job satisfaction and burnout, self-efficacy, and beliefs, attitudes, and skills related to EBP competency. Taken together, the authors' findings promote a nuanced approach to program implementation that takes into account the needs of both student clients and school consultees. Rather than presuming that consultees are equipped and motivated to collaborate on EBPs, contemporary approaches to consultation/coaching are expanding to include professional development strategies to prepare school staff for the changes that EBPs require. The resulting impact on the consultative relationship and student outcomes is still 
unclear, but the articles in this special issue offer important insight into these vital questions.

\section{References}

Becker, K. D., Bradshaw, C., Domitrovich, C., \& Ialongo, N. S. (2013). Coaching teachers to improve implementation of the good behavior game. Administration and Policy in Mental Health and Mental Health Services Research, 40, 482-493. doi:10.1007/s10488-013-0482-8.

Beidas, R. S., \& Kendall, P. C. (2010). Training therapists in evidence-based practice: A critical review of studies from a systems-contextual perspective. Clinical Psychology: Science \& Practice, 17, 1-30. doi:10.1111/j.1468-2850.2009.01187.x.

Burns, B. J., Costello, E. J., Angold, A., Tweed, D., Stangl, D., Farmer, E. M., \& Erkanli, A. (1995). Children's mental health services use across service sectors. Health Affairs, 14(3), 147-159. doi:10.1377/hlthaff.14.3.147.

Capella, E., Hamre, B., Kim, H., Henry, D., Frazier, S., Atkins, M., \& Schoenwald, S. (2012). Teacher consultation and coaching within mental health practice: Classroom and child effects in urban elementary schools. Journal of Consulting and Clinical Psychology, 80, 597-610. doi:10.1037/a0027725.

Coles, E. K., Owens, J. S., Serrano, V. J., Slavec, J., \& Evans, S. W. (2015). From consultation to student outcomes: The role of teacher knowledge, skills, and beliefs in increasing integrity in classroom management strategies. School Mental Health. doi:10. 1007/s12310-015-9143-2.

Cook, C. R., Lyon, A. R., Kubergovic, D., Wright, D. B., \& Zhang, Y. (2015). A supportive beliefs intervention to facilitate the implementation of evidence-based practices within a multitiered system of supports. School Mental Health. doi:10.1007/ s12310-014-9139-3.

Eccles, M. P., \& Mittman, B. S. (2006). Welcome to implementation science. Implementation Science, 1(1), 1-3. doi:10.1186/17485908-1-1.

Erchul, W. P. (2015). Put me in coach: Observations on selected studies implementing supportive interventions to teachers. School Mental Health. doi:10.1007/s12310-015-9144-1.

Erchul, W. P., \& Raven, B. H. (1997). Social power in school consultation: A contemporary view of French and Raven's bases of power model. Journal of School Psychology, 35(2), 137-171. doi:10.1016/s0022-4405(97)00002-2.

Erchul, W. P., Raven, B. H., \& Ray, A. G. (2001a). School psychologists' perceptions of social power bases in teacher consultation. Journal of Educational and Psychological Consultation, 12, 1-23. doi:10.1207/s1532768xjepc1201_01.

Erchul, W. P., Raven, B. H., \& Whichard, S. M. (2001b). School psychologists and teachers perceptions of social power bases in school consultation. Journal of School Psychology, 39, 483-497. doi:10.1016/s0022-4405(01)00085-1.

Erchul, W. P., Raven, B. H., \& Wilson, K. E. (2004). The relationship between gender of consultant and social power perceptions within school consultation. School Psychology Review, 33, 582-590.

Fixsen, D. L., Naoom, S. F., Blase, K. A., Friedman, R. M., \& Wallace, F. (2005). Implementation research: A synthesis of the literature. (FMHI Publication \#231). Tampa, FL: University of South Florida, Louis de la Parte Florida Mental Health Institute, The National Implementation Research Network.

Forman, S. G., Olin, S. S., Hoagwood, K. E., Crowe, M., \& Saka, N. (2009). Evidence-based interventions in schools: Developer's views of implementation barriers and facilitators. School Mental Health, 1, 26-36.

Forman, S. G., Shapiro, E. S., Codding, R. S., Gonzales, J. E., Reddy, L. A., Rosenfield, S. A., et al. (2013). Implementation science and school psychology. School Psychology Quarterly, 28, 77-100. doi:10.1037/spq0000019.

Greenberg, M. T., Weissberg, R. P., O'Brien, M. U., Zins, J. E., Fredericks, L., Resnik, H., \& Elias, M. J. (2003). Enhancing school-based prevention and youth development through coordinated social, emotional, and academic learning. American Psychologist, 58, 466-474. doi:10.1037/0003-066x.58.6-7.466.

Greenhalgh, T., Robert, G., MacFarlane, F., Bate, P., \& Kyriakidou, O. (2004). Diffusion of innovations in service organizations: Systematic review and recommendations. The Milbank Quarterly, 82, 581-629. doi:10.1111/j.0887-378x.2004.00325.x.

Kazdin, A. E. (2008). Evidence-based treatment and practice: New opportunities to bridge clinical research and practice, enhance the knowledge base, and improve patient care. American Psychologist, 63, 146-159. doi:10.1037/0003-066x.63.3.146.

Mashburn, A., Downer, J., Hamre, B., Justice, L., \& Pianta, R. (2010). Consultation for teachers and children's language and literacy development during pre-kindergarten. Applied Developmental Science, 14, 179-196. doi:10.1080/10888691.2010.516187.

Miller, W. R., Yahne, C. E., Moyers, T. B., Marinez, J., \& Pirritano, M. (2004). A randomized trial of methods to help clinicians learn motivational interviewing. Journal of Consulting and Clinical Psychology, 72, 1050-1062. doi:10.1037/0022-006x.72.6.1050.

National Association of School Psychologists. (2008). The importance of school mental health services (position statement). Bethesda, MD: National Association of School Psychologists.

Noell, G. H., Witt, J. C., LaFleur, L. H., Mortenson, B. P., Ranier, D. D., \& LeVelle, J. (2000). Increasing intervention implementation in general education following consultation: A comparison of two follow-up strategies. Journal of Applied Behavior Analysis, 33, 271-284. doi:10.1901/jaba.2000.33-271.

Owens, J. S., Lyon, A. R., Brandt, N. C., Warner, C. M., Nadeem, E., Spiel, C., \& Wagner, M. (2013). Implementation science in school mental health: Key constructs in a developing research agenda. School Mental Health, 6(2), 99-111. doi:10.1007/ s12310-013-9115-3.

Pas, E. T., Bradshaw, C. P., Becker, K. D., Domitrovich, C. E., Berg, J., Musci, R., \& Ialongo, N. S. (2015). Identifying patterns of coaching to support the implementation of the Good Behavior Game: The role of teacher characteristics. School Mental Health. doi:10.1007/s12310-015-9145-0.

President's New Freedom Commission on Mental Health. (2003). Achieving the promise: Transforming mental health care in America. Final report (DHHS Publication No. SMA-03-3832). Rockville, MD: U.S. Department of Health and Human Services. doi: 10.1037/e513572010-001

Raver, C. C., Jones, S. T., Li-Grining, C., Zhai, F., Metzger, M., \& Solomon, B. (2009). Targeting children's behavior problems in preschool classrooms: A cluster-randomized controlled trial. Journal of Consulting and Clinical Psychology, 77, 302-316. doi:10.1037/a0015302.

Ravthon, N. (2008). Effective school interventions: Evidence-based strategies for improving student outcomes (2nd ed.). New York: Guildford.

Rones, M., \& Hoagwood, K. (2000). School-based mental health services: A research review. Clinical Child and Family Psychology Review, 3(4), 223-241. doi:10.1023/a:1026425104386.

Schoenwald, S. K., Sheidow, A. S., \& Letourneau, E. J. (2004). Toward effective quality assurance in evidence-based practice: Links between expert consultation, therapist fidelity, and child outcomes. Journal of Child and Adolescent Clinical Psychology, 33, 94-104. doi:10.1207/s15374424jccp3301_10. 
Schultz, B. K., Reisweber, J., \& Cobb, H. (2008). Mental health consultation in secondary schools. In S. Evans, M. Weist, \& Z. Serpell (Eds.), Advances in school-based mental health interventions (Vol. 2). New York: Civic Research Institute.

Shernoff, E. S., Lakind, D., Frazier, S. L., \& Jacobsons, L. (2015). Coaching early career teachers in urban elementary schools: A mixed-method study. School Mental Health. doi:10.1007/ s12310-014-9136-6.

Solomon, B. G., Klein, S. A., \& Politylo, B. C. (2012). The effect of performance feedback on teachers' treatment integrity: A metaanalysis of the single-case literature. School Psychology Review, $41,160-175$.

Sutherland, K. S., Conroy, M. A., Vo, A., \& Ladig, C. (2015). Implementation integrity of practice-based coaching:
Preliminary results from the BEST in CLASS efficacy trial. School Mental Health. doi:10.1007/s12310-014-9134-8.

van Oorsouw, W., Embregts, P., Bosman, A. M. T., \& Jahoda, A. (2009). Training staff serving clients with intellectual disabilities: A meta-analysis of aspects determining effectiveness. Research in Developmental Disabilities, 30, 503-511. doi:10. 1016/j.ridd.2008.07.011.

Weissman, M. M., Verdeli, H., Gameroff, M. J., Bledsoe, S. E., Betts, K., Mufson, L., et al. (2006). National survey of psychotherapy training in psychiatry, psychology, and social work. Archives of General Psychiatry, 63, 925-934. doi:10.1001/archpsyc.63.8.925. 